\title{
Generation of pancreatic insulin-producing cells from rhesus monkey induced pluripotent stem cells
}

\author{
F. F. Zhu • P. B. Zhang $\cdot$ D. H. Zhang $\cdot$ X. Sui $\cdot$ M. Yin • \\ T. T. Xiang $\cdot$ Y. Shi $\cdot$ M. X. Ding $\cdot$ H. Deng
}

Received: 5 January 2011 / Accepted: 16 June 2011 / Published online: 14 July 2011

(C) Springer-Verlag 2011

\begin{abstract}
Aims/hypothesis The generation of induced pluripotent stem cells (iPSCs) provides a promising possibility for type 1 diabetes therapy. However, the generation of insulinproducing cells from iPSCs and evaluation of their efficacy and safety should be achieved in large animals before clinically applying iPSC-derived cells in humans. Here we try to generate insulin-producing cells from rhesus monkey (RM) iPSCs.

Methods Based on the knowledge of embryonic pancreatic development, we developed a four-stage protocol to generate insulin-producing cells from RM iPSCs. We established a quantitative method using flow cytometry to analyse the differentiation efficiency. In addition, to evaluate the differentiation competence and function of RM iPSC-derived cells, transplantation of stage 3 and 4 cells into immunodeficient mice was performed.

Results RM iPSCs were sequentially induced to definitive endoderm (DE), pancreatic progenitors (PP), endocrine pre-
\end{abstract}

F. F. Zhu, P. B. Zhang and D. H. Zhang contributed equally to this study.

Electronic supplementary material The online version of this article (doi:10.1007/s00125-011-2246-x) contains peer-reviewed but unedited supplementary material, which is available to authorised users.

F. F. Zhu • D. H. Zhang $\cdot$ X. Sui $\cdot$ Y. Shi $\cdot$ H. Deng

Laboratory of Chemical Genomics,

Shenzhen Graduate School of Peking University,

Shenzhen, People's Republic of China

F. F. Zhu $\cdot$ P. B. Zhang $\cdot$ D. H. Zhang $\cdot$ X. Sui $\cdot$ M. Yin $\cdot$

T. T. Xiang $\cdot$ M. X. Ding $\cdot$ H. Deng $(\bowtie)$

Key Laboratory of Cell Proliferation and Differentiation of the Ministry of Education, Department of Cell Biology and Genetics,

College of Life Sciences, Peking University,

Beijing 100871, People's Republic of China

e-mail: hongkui_deng@pku.edu.cn cursors (EP) and insulin-producing cells. $\mathrm{PDX1} 1^{+} \mathrm{PP}$ cells were obtained efficiently from RM iPSCs (over $85 \%$ efficiency). The TGF- $\beta$ inhibitor SB431542 promoted the generation of $\mathrm{NGN}^{+}$EP cells, which can generate insulin-producing cells in vivo upon transplantation. Finally, after this fourstage differentiation in vitro, insulin-producing cells that could secrete insulin in response to glucose stimulation were obtained. When transplanted into mouse models for diabetes, these insulin-producing cells could decrease blood glucose levels in approximately $50 \%$ of the mice. Conclusions/interpretation We demonstrate for the first time that RM iPSCs can be differentiated into functional insulin-producing cells, which will provide the basis for investigating the efficacy and safety of autologous iPSCderived insulin-producing cells in a rhesus monkey model for type 1 diabetes therapy.

Keywords Induced pluripotent stem cells $\cdot$ Pancreatic insulin-producing cells $\cdot$ Rhesus monkey SB431542 .

Type 1 diabetes

$\begin{array}{ll}\text { Abbreviations } \\ \text { AFP } & \alpha \text {-Fetoprotein } \\ \text { CXCR4 } & \text { Chemokine (C-X-C motif) receptor } 4 \\ \text { DE } & \text { Definitive endoderm } \\ \text { EP } & \text { Endocrine precursor } \\ \text { ESCs } & \text { Embryonic stem cells } \\ \text { FOXA2 } & \text { Forkhead box A2 protein } \\ \text { GATA6 } & \text { GATA binding protein } 6 \\ \text { GCG } & \text { Glucagon } \\ \text { HGF } & \text { Hepatocyte growth factor } \\ \text { HNF } & \text { Hepatic nuclear factor } \\ \text { iPSCs } & \text { Induced pluripotent stem cells } \\ \text { KGF } & \text { Keratinocyte growth factor } \\ \text { KLF4 } & \text { Kruppel-like factor } 4\end{array}$




$\begin{array}{ll}\text { MEF } & \text { Mouse embryonic fibroblast } \\ \text { NKX2-2 } & \text { NK2 homeobox 2 } \\ \text { NKX6-1 } & \text { NK6 homeobox 1 } \\ \text { NOD/SCID } & \begin{array}{l}\text { Non-obese diabetic/severe combined } \\ \text { immunodeficient }\end{array} \\ \text { OCT } & \text { Octamer binding protein } \\ \text { PDX1 } & \text { Pancreatic and duodenal homeobox 1 } \\ \text { PP } & \text { Pancreatic progenitor } \\ \text { RA } & \text { Retinoic acid } \\ \text { RM iPSCs } & \text { Rhesus monkey iPSCs } \\ \text { SOX } & \text { SRY-box containing gene } \\ \text { STZ } & \text { Streptozotocin } \\ \text { WNT3A } & \text { Wingless-related MMTV integration } \\ & \text { site 3A }\end{array}$

\section{Introduction}

Induced pluripotent stem cells (iPSCs) can be generated directly from somatic cells [1-4], which makes it possible to obtain patient-specific multipotent cells and differentiate these cells into particular lineages for cell replacement therapy and avoid the problems of donor cell shortage, immune rejection and ethical debates related to procedures using human embryos. Disease-specific iPSCs have been established from individual patients [5-9], and differentiation of human iPSCs into lineage-specific cells has been achieved [10-13]. However, the efficacy and safety of iPSC-derived cells in clinical applications in human disease therapies must first be evaluated using animal models.

So far, in mouse models, lineage-specific cells have been differentiated from iPSCs to cure several types of disease including sickle cell anaemia [14], Parkinson's disease [15], haemophilia A [16] and diabetes [17]. However, rodent models cannot fully recapitulate human diseases and there have not yet been reports of iPSC application research in large animal models.

The rhesus monkey (Macaca mulatta, rhesus macaque), one of the most frequently and thoroughly studied model species of all non-human primates, is a suitable candidate. It shares approximately $93 \%$ of its DNA sequence with humans and exhibits greater similarity to human physiology and susceptibility to infectious and metabolic diseases than rodents do. Moreover, we demonstrated in our previous study that rhesus monkey (RM) iPSCs can be generated by transduction of the same four transcription factors used in humans [18]. Given these similarities, the rhesus monkey is a very relevant primate model and would help in the investigation of iPSC therapeutic application in certain diseases, such as type 1 diabetes.

Type 1 diabetes is caused by the autoimmune destruction of beta cells in the pancreas. Pancreatic islet transplantation is a promising therapy for type 1 diabetes, because it has been demonstrated to allow insulin independence with glycaemic control in some patients for over 2 years [19]. However, the extreme lack of donor beta cells and the threat of immune rejection impede its widespread application. To solve these problems, several studies have attempted the pancreatic differentiation of human iPSCs $[9,12,20]$ based on protocols used in human embryonic stem cell (ESC) pancreatic differentiation [20-22], and obtained insulinproducing cells with some characteristics of islet beta cells. However, no functional studies of these iPSC-derived insulin-producing cells using in vivo transplantation were performed in these studies.

In the present study, we established a new four-stage protocol to differentiate RM iPSCs to generate definitive endoderm (DE), pancreatic progenitors (PP) and endocrine precursors (EP), and then to further induce these EP cells into insulin-producing cells by both in vivo maturation and in vitro differentiation. Moreover, the RM iPSC in vitroderived insulin-producing cells can secrete insulin in response to glucose stimulation, and rescue hyperglycaemia in approximately $50 \%$ of streptozotocin (STZ)-treated diabetic mice. To our knowledge, this is the first report detailing the generation of functional insulin-producing cells from primate iPSCs, and will provide the basis for achieving proof of principle of iPSC-based therapy for type 1 diabetes in large animal models.

\section{Methods}

Animals Six- to 8-week old male NOD/SCID mice (Vital River Laboratories, Beijing, China) were used for transplantation, and all animal procedures were approved by the Institutional Animal Care and Use Committee of Peking University.

Generation and maintenance of RM iPSCs The detailed protocol for establishing RM iPSCs has been described previously [18].

Directed differentiation of RM iPSCs into pancreatic insulin-producing cells The differentiation protocol is described in Fig. 1a. The media used here, RPMI1640, DF12 and DMEM, were all supplemented with $2 \mathrm{mmol} / \mathrm{l}$ Glutamax, $0.1 \mathrm{mmol} / 1$ non-essential amino acids, $55 \mu \mathrm{mol} / 1$ betamercaptoethanol and penicillin/streptomycin. DF12 and DMEM were also supplemented with $1 \%$ B27 (all from Gibco, Carlsbad, CA, USA).

In step 1, the undifferentiated iPSCs were treated with 100 ng/ml activin A (PeproTech, Rocky Hill, NJ, USA) and $25 \mathrm{ng} / \mathrm{ml}$ wingless-related MMTV integration site 3A (WNT3A) (R\&D Systems, Minneapolis, MN, USA) in 
Fig. 1 The scheme of RM iPSC differentiation into insulinproducing cells. a The differentiation protocol is divided into four stages, and the growth factors and duration for each stage of differentiation are shown. EX4, exendin-4; Nico, nicotinamide. b-j Quantitative PCR analysis showed the dynamic expression of several key genes during pancreatic beta cell development. For each gene, the sample with the highest expression level was set to 1 , and the other samples were normalised to this level. Data represent mean $\pm \mathrm{SD}$, and error bars indicate SD. Undif, undifferentiated. Similar results were obtained in at least three independent experiments

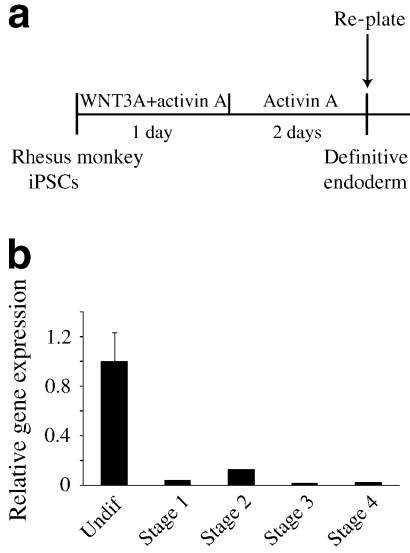

OCT3/4

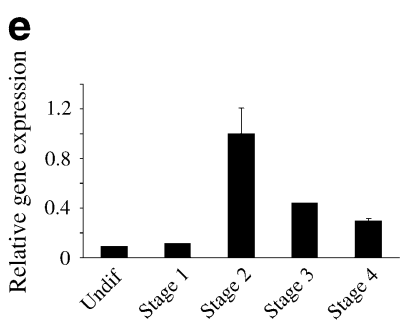

PDX1

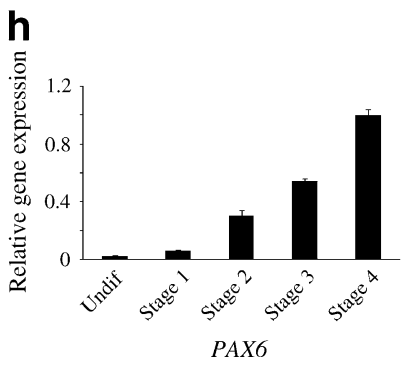

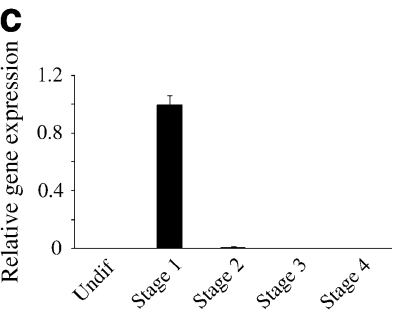

SOX17

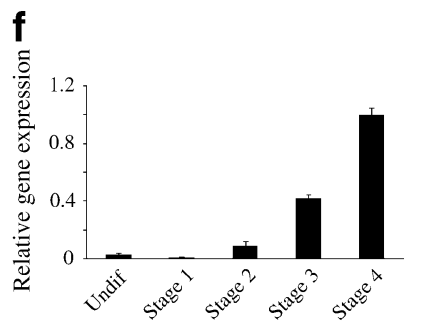

NKX6-1
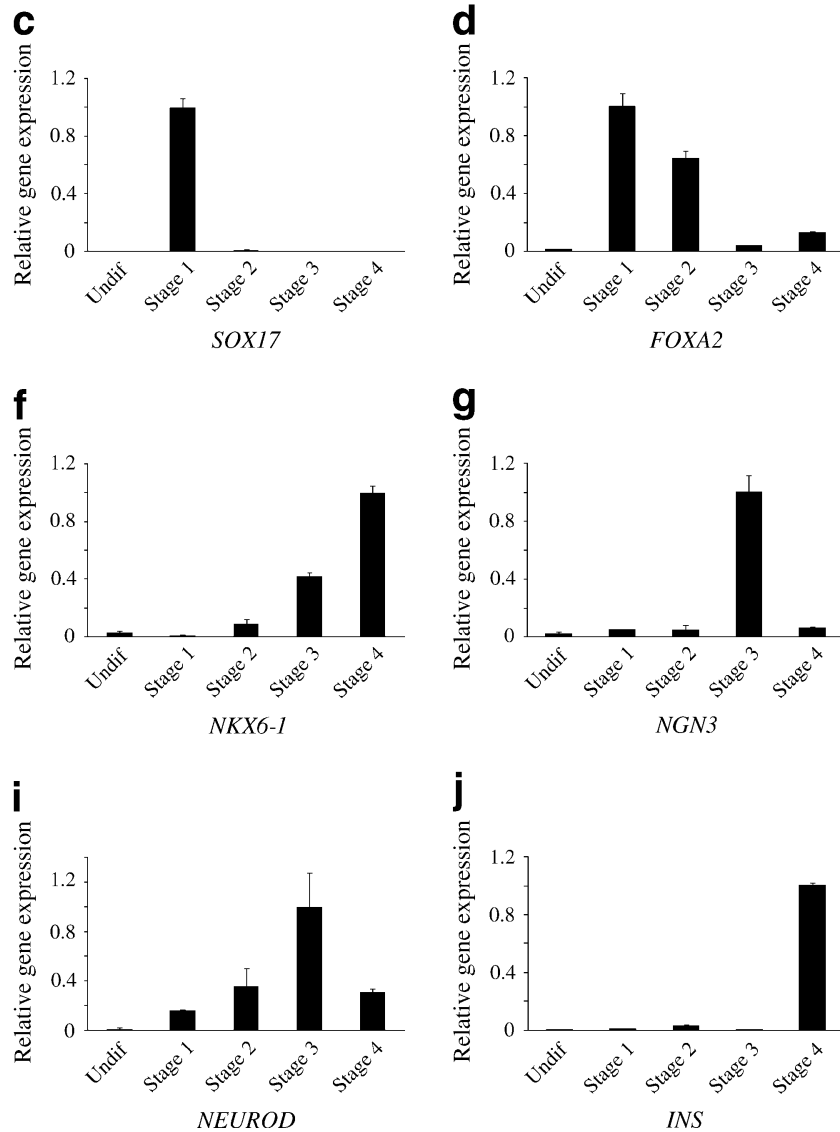

FOXA2

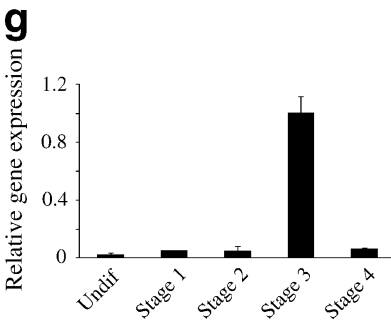

NGN3

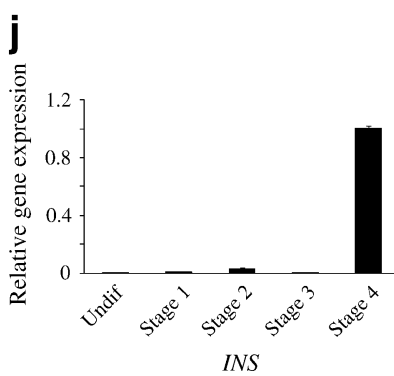

RPMI1640 for 1 day. On the following 2 days, $100 \mathrm{ng} / \mathrm{ml}$ activin A was added, supplemented with $0.2 \%$ FBS. Cells were then digested with $0.25 \%$ trypsin (Gibco) into single cells and seeded at a density of $0.5 \times 10^{5}$ to $1 \times 10^{5}$ cells per well of a 48 -well plate on mouse embryonic fibroblast (MEF) feeders. In step 2, the cells were cultured in DF12 supplemented with $2 \mu \mathrm{mol} / 1$ all-trans retinoic acid (RA; Sigma, St Louis, MO, USA) and $50 \mathrm{ng} / \mathrm{ml}$ keratinocyte growth factor (KGF; PeproTech) for 6 days. Following this, in step 3, cells were treated with $50 \mathrm{ng} / \mathrm{ml}$ EGF (PeproTech) and $1 \mu \mathrm{mol} / 1 \mathrm{SB} 431542$ (Tocris Bioscience, Ellisville, MO, USA) in DMEM for 5 days and, in the final step, the cells were incubated in DMEM with $50 \mathrm{ng} / \mathrm{ml}$ hepatocyte growth factor (HGF; PeproTech), 50 ng/ml IGF1 (PeproTech), $50 \mathrm{ng} / \mathrm{ml}$ exendin-4 (Sigma) and $10 \mathrm{mmol} / \mathrm{l}$ nicotinamide (Sigma) for 7 days.

The in vitro differentiation experiments were carried out using R14 and R19 cell lines and repeated more than five times. Similar results were obtained and data presented are from R14, unless otherwise indicated.
Immunofluorescence The differentiated RM iPSCs were briefly washed with PBS, fixed in 4\% (wt/vol.) paraformaldehyde for 20-30 min, washed three times in PBS, and blocked with PBST (PBS/0.1\% Triton X-100 [Sigma]) containing 3\% normal donkey serum (Jackson ImmunoResearch Laboratory, West Grove, PA, USA) for $60 \mathrm{~min}$. Cells were incubated with primary antibodies in PBST overnight at $4^{\circ} \mathrm{C}$ and then washed three times. They were then incubated with secondary antibodies in PBS containing $0.1 \%$ BSA (Jackson ImmunoResearch Laboratory) for $1 \mathrm{~h}$ at room temperature, avoiding exposure to light. Afterwards, cells were washed with PBS. The nuclei were stained with $1 \mu \mathrm{g} / \mathrm{ml}$ DAPI (Roche Applied Science, Indianapolis, IN, USA) for $5 \mathrm{~min}$. Images were captured by a Nikon Eclipse TE2000-U fluorescence microscope (Nikon, Tokyo, Japan) or a Leica confocal microscope TCS-SP2 (Leica, Solms, Germany).

The primary and secondary antibodies are described in the Electronic supplementary material (ESM) Tables 1 and 2, respectively. 
Flow cytometry For surface marker staining, cells were digested with $0.25 \%$ trypsin into single cells. After being washed, the cells were incubated in $200 \mu \mathrm{l}$ PBS containing $0.5 \%$ BSA for $15 \mathrm{~min}$ and then stained with phycoerythrin-conjugated mouse anti-human chemokine (C-X-C motif) receptor 4 (CXCR4) antibody (BD Biosciences, Bedford, MA, USA) and allophycocyanin (APC)-conjugated mouse anti-human kinase insert domain receptor (KDR) (R\&D Systems), CD117 (BD Biosciences) or CD140a (BD Biosciences) antibodies at $5 \mu 1 / 2 \times 10^{5}$ cells for $30 \mathrm{~min}$ at $4^{\circ} \mathrm{C}$. Cells were then washed three times and resuspended in $300 \mu \mathrm{l}$ PBS for analysis.

The intracellular staining was performed using Cytofix/ Cytoperm and Perm/Wash buffer (BD Biosciences) according to the manufacturer's instructions. The primary and secondary antibodies are described in ESM Tables 1 and 2, respectively.

Data were acquired on a FACS Calibur (BD Biosciences) and were analysed using CellQuest software (BD Biosciences). At least three independent experiments were carried out for each test.

Real-time quantitative PCR RNA was isolated using the RNeasy Plus Mini Kit (Qiagen, Valencia, CA, USA) following the manufacturer's instructions. Following this, $2 \mu \mathrm{g}$ RNA was reverse transcribed using the EasyScript First-Strand cDNA Synthesis SuperMix (Beijing Transgen Biotech, Beijing, China). Real-time PCR was performed using the ABI Prism 7300 Sequence Detection System. The primer sequences were designed according to the corresponding human genes and are shown in ESM Table 3. PCR was performed in duplicate for each sample, and three independent experiments were carried out.

Glucose-stimulated insulin secretion and intracellular insulin content analysis To analyse glucose-stimulated insulin secretion, cells were washed twice with PBS and first incubated with Krebs-Ringer buffer free of glucose for $60 \mathrm{~min}$ at $37^{\circ} \mathrm{C}$. The cells were then incubated with Krebs-Ringer buffer containing low $(2.5 \mathrm{mmol} / \mathrm{l})$ or high $(25 \mathrm{mmol} / \mathrm{l})$ concentrations of glucose for $60 \mathrm{~min}$ at $37^{\circ} \mathrm{C}$ and supernatant fractions were collected. To analyse the intracellular content of insulin, the final stage cells ware treated with lysis buffer. The assays for the insulin content were performed using an Insulin ELISA kit (Mercodia, Uppsala, Sweden).

Transplantation Cells were transplanted into NOD/SCID mice. Differentiated cells were digested with $1 \mathrm{mg} / \mathrm{ml}$ dispase (Gibco) and resuspended in ultra-low dishes (Corning, Corning, NY, USA) the day before transplantation.
Diabetes was induced by intraperitoneal injection of $120 \mathrm{mg} / \mathrm{kg}$ body weight STZ (Sigma) in NOD/SCID mice. The experimental group had about $0.5 \times 10^{7}$ to $1 \times 10^{7}$ differentiated cells implanted under the left kidney capsule, and the control group experienced a similar operation with transplantations of PBS. The blood glucose levels were monitored weekly with glucometer strips (Accu-check, Roche) using blood from snipped tails.

The grafts were examined after 8-10 weeks. The kidneys bearing the grafts were embedded in OCT (optimal cutting temperature) compound (Sakura, Torrance, CA, USA) and cut into cryostat sections. Immunofluorescence analyses were performed to detect the expression of pancreatic endocrine hormones and transcription factors. The antibody information can be found in ESM Tables 1 and 2 .

Statistical analysis For insulin release data, a two-tailed unpaired Student's $t$ test was used for statistical evaluation. For gene expression comparison among different treatments, statistical analysis was performed using a one-way ANOVA, with Duncan's multiple range post-hoc tests. In all statistical analyses, $p<0.05$ was considered statistically significant.

\section{Results}

Screening of RM iPSCs for pancreatic differentiation We generated RM iPSCs by retrovirus-mediated transduction of the monkey transcription factors octamer binding protein (OCT)3/4, SRY-box containing gene (SOX)2, Kruppel-like factor 4 (KLF4) and c-MYC into the adult fibroblasts as previously described [18].

Because it has been reported that different human ESC and iPSC lines vary in their capacity for differentiation $[10,23]$, we performed a screen of the RM iPSCs to select cell lines for pancreatic differentiation. Nineteen RM iPSC lines from the same rhesus monkey were induced to generate DE cells and analysed by flow cytometry for chemokine (C-X-C motif) receptor 4 (CXCR4) abundance. As shown in ESM Fig. 1, these RM iPSCs exhibited various levels of CXCR4 and approximately four- to fivefold differences were observed. Among these cells, R14 and R19 showed the highest CXCR4 levels of over $90 \%$ and also exhibited the greatest ability to generate pancreatic and duodenal homeobox 1 (PDX1) ${ }^{+}$PP cells upon further differentiation (data not shown). Therefore, R14 and R19 were chosen for the pancreatic differentiation study.

Establishment of a new four-stage differentiation protocol Using current knowledge of signalling regulation in embry- 
onic pancreatic development, we established a four-stage protocol for RM iPSC differentiation into pancreatic insulinproducing cells (Fig. 1a), with steps 1 and 4 similar to the ViaCyte protocol [24]. The following four stages, DE induction, PP generation, EP specification and insulinproducing cell maturation, recapitulate the embryonic pancreatic beta cell development very well [25]. Gene expression analyses showed that, during this differentiation, RM iPSCs rapidly lost expression of the pluripotent gene OCT3/4 (also known as POU5F1) and stage-specific marker genes exhibited the highest expression levels in their corresponding stages, such as $S O X 17$ for the DE stage, $P D X 1$ for the PP stage, $N G N 3$ (also known as NEUROG3) for the EP stage and INS for the final stage (Fig. 1b-j).

\section{Efficient generation of DE and PP cells from RM iPSCs In} stage 1, RM iPSCs were treated with activin A and WNT3A for DE induction, and to monitor this process, we followed gene expression changes by immunochemistry during this 3 day period. Brachyury, the mesendoderm marker, was produced in a large portion of cells after 1 day of differentiation and the number of cells producing this marker gradually decreased, while the number of SOX $17^{+}$ (protein encoded by SRY-box containing gene 17) cells increased at day 2. At the end of day 3, over $90 \%$ of the differentiated RM iPSCs were SOX $17^{+}$and no Brachyury ${ }^{+}$ cells remained (ESM Fig. 2a). Moreover, the SOX $17^{+}$cells were positive for forkhead box A2 (FOXA2), but negative for $\alpha$-fetoprotein (AFP) (ESM Fig. 2b,c), excluding the presence of extraembryonic endoderm cells. Flow cytometry analysis showed that there were about $94.4 \%(92.2 \% \pm$ $4.1 \%, n=5) \mathrm{CXCR}^{+} \mathrm{CD} 117^{+}$cells. These $\mathrm{CXCR} 4^{+} \mathrm{CD} 117^{+}$ cells did not express the mesoderm markers KDR or CD140a (ESM Fig. 2d), suggesting that no mesoderm cells were induced. Therefore, RM iPSCs can be differentiated into DE cells efficiently.

In step 2, we used the method established in our laboratory, which added a dissociation treatment after step 1 to obtain high efficiency of $\mathrm{PDX}^{+}$cells [26]. The induced DE cells from RM iPSCs were trypsinised into single cells, replated onto MEF feeders, and subjected to RA and KGF treatment for 6 days. At the end of this stage, the replated cells expanded and formed clusters, which exhibited much higher efficiency of generating $\mathrm{PDX}^{+}$ cells (Fig. 2a) than those cells without dissociation treatment (ESM Fig. 3a). Further experiments showed that most of these $\mathrm{PDX} 1^{+}$cells produced SOX9, FOXA2, hepatic nuclear factor (HNF) 4 alpha, HNF6 and GATA binding protein 6 (GATA6) (Fig. 2a-e), but did not produce AFP or causal type homeobox 2 (CDX2) (ESM Fig. 3b,c), indicating that these $\mathrm{PDX}^{+}$cells are PP cells. In addition, flow cytometry analysis showed that about $87.5 \%(82.5 \% \pm 6.0 \%, n=5)$ of the cells became PDX1 positive (Fig. 2f). These results suggest that RM iPSCs can be efficiently differentiated from DE cells to PP cells.

SB431542 promotes the generation of $N G N 3^{+}$EP cells We have previously identified EGF as being able to expand the $\mathrm{PDX}^{+}$PP cells [20]. In addition, activation of the TGF- $\beta$ pathway could stimulate PP cells to experience exocrine differentiation, while decreasing the generation of EP cells [27]. Therefore, we treated the $\mathrm{PDX} 1^{+} \mathrm{PP}$ cells with both EGF and the TGF- $\beta$ inhibitor SB431542 to promote the generation of $\mathrm{NGN}^{+}{ }^{+}$(NEUROG3 protein) EP cells. Realtime PCR analysis indicated that this combination could increase the expression levels of NGN3, PDX1, HNF6 (also known as ONECUT1), NKX6-1 and PAX6, compared with single-factor treatment (ESM Fig. 4a-e).

We then tested the production of important endocrine transcription factors by immunocytochemistry. As previously reported, cells co-producing HNF6 and PDX1 are considered the progenitors of the NGN3-producing cells [28], and NGN3 is used as an EP marker [29, 30]. In this stage, cells positive for PDX1 and HNF6 were detected (Fig. 3a). NGN3-producing cells appeared in the domains of the $\mathrm{HNF}^{+}$cells and the $\mathrm{PDX}^{+}$cells (Fig. 3b,c). However, not all $\mathrm{HNF}^{+}$or $\mathrm{PDX}^{+}$cells produced NGN3, and there were also a few $\mathrm{NGN}^{+}$cells that did not produce PDX1 or HNF6. In addition, NK6 homeobox 1 (NKX6-1) and NK2 homeobox 2 (NKX2-2) were detected in the clusters of $\mathrm{PDX}^{+}$cells (Fig. $3 \mathrm{~d}, \mathrm{e}$ ). Therefore, these results suggested that endocrine specification of RM iPSCs can be achieved.

We then questioned whether RM iPSC-derived EP cells can differentiate into insulin-producing cells in vivo. Stage 3 cells were implanted into the kidney capsules of NOD/SCID mice. Approximately 2 months later, these implanted cells formed compact grafts in most of the mice, and the insulin-producing cells were detected with cluster morphology and produced NKX6-1 and C-peptide (Fig. 4a,b). Meanwhile, these insulinpositive $\left(\mathrm{INS}^{+}\right)$cells did not produce glucagon. However, it seems that a few $\mathrm{INS}^{+}$cells produced somatostatin. In some areas, cells producing glucagon or somatostatin, but not insulin, were observed (Fig. 4c-e). We also found a few cells producing proinsulin (ESM Fig. 5a). In ductstructure areas, cells producing CK19 were observed (ESM Fig. 5b). These results showed that EP cells are competent to generate insulin-producing cells in vivo.

Generation and characterisation of insulin-producing cells in vitro To obtain insulin-producing cells in vitro, the stage 3 EP cells were incubated with exendin-4, nicotinamide, HGF and IGF1 for 7 days. Following this, insulinproducing cells were observed, which produced C-peptide, indicating the de novo synthesis of insulin, as opposed to 
Fig. 2 RM iPSC-derived DE efficiently differentiates into PP cells. a-e Most of the PDX1producing $\mathrm{PP}$ cells produce SOX9, FOXA2, HNF6, HNF4A and GATA6. f Flow cytometry analysis showed that, at the end of stage 2, approximately $87.5 \%$ of the cells are PDX $1^{+} \mathrm{PP}$ cells. Scale bars, $30 \mu \mathrm{m}$. Undif, undifferentiated; Dif, differentiated; FL1-H, height of

fluorescence intensity. Similar results were obtained in at least three independent experiments a
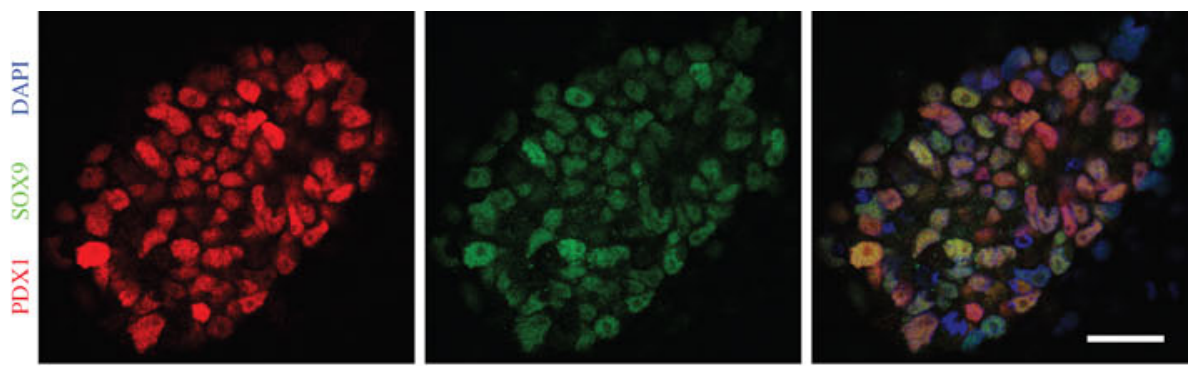

b
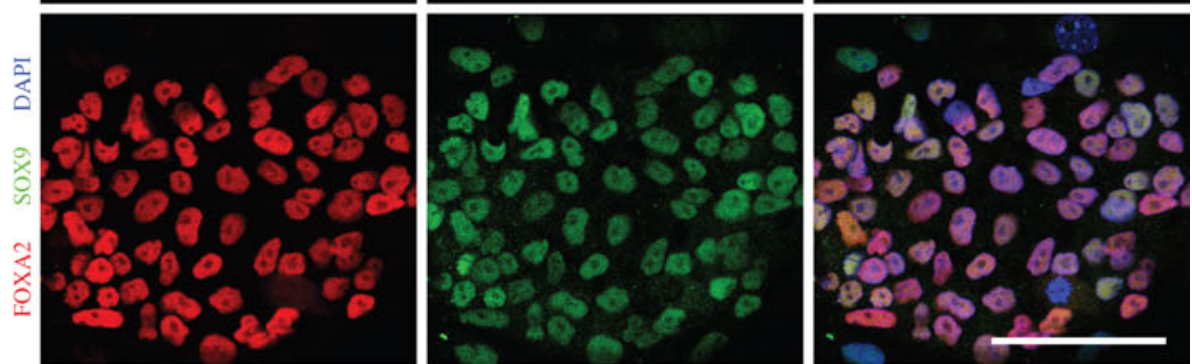

C
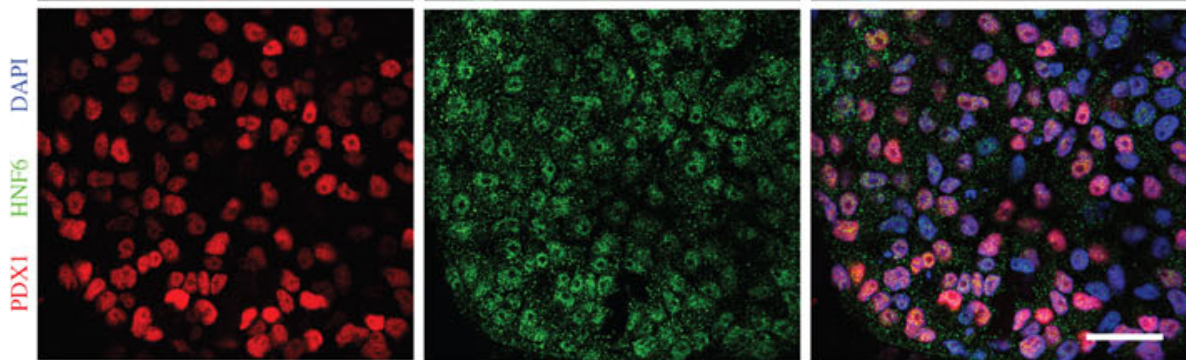

d
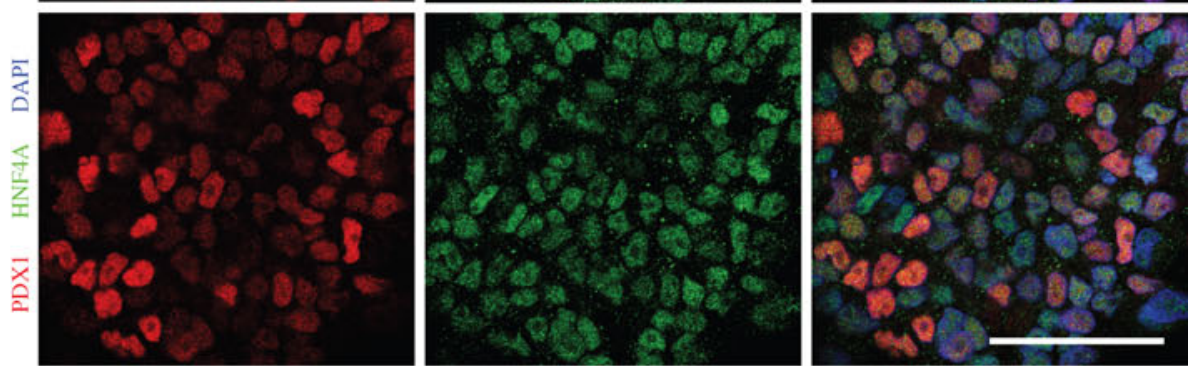

e
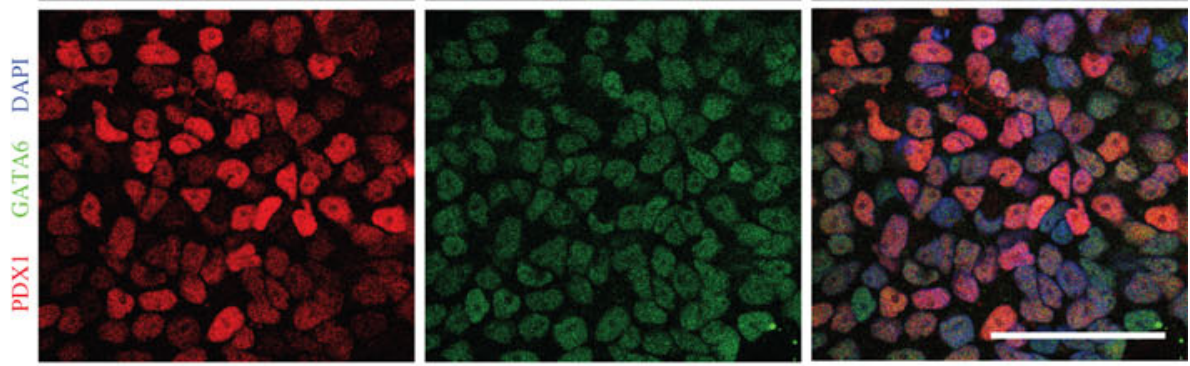

f

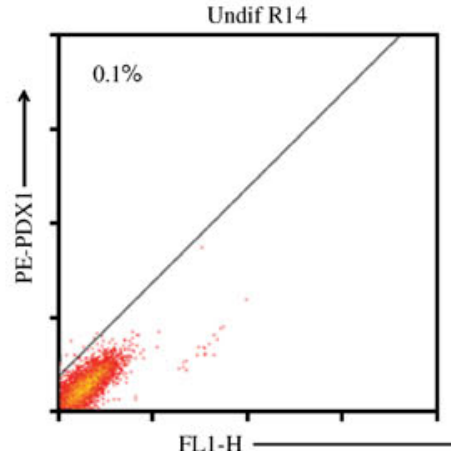

D9 Dif R14

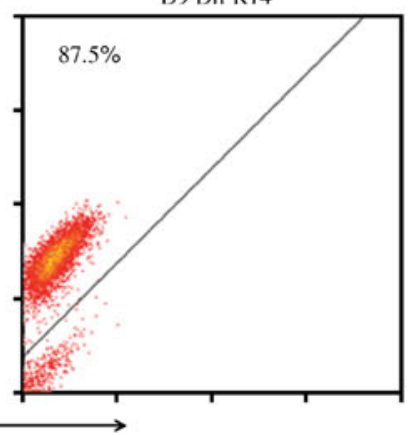


Fig. 3 RM iPSC-derived PPs differentiate into EPs. a-c Immunocytochemistry analysis showed that, at the end of stage 3, cells co-producing PDX1 and HNF6 could be detected, most of which were also positive for NGN3. d, e Many $\mathrm{PDX}^{+}$cells also produce NKX6-1 and NKX2-2. Scale bars, $50 \mu \mathrm{m}$ (b), and $100 \mu \mathrm{m}$ (a, c-e). Similar results were obtained in at least three independent experiments a
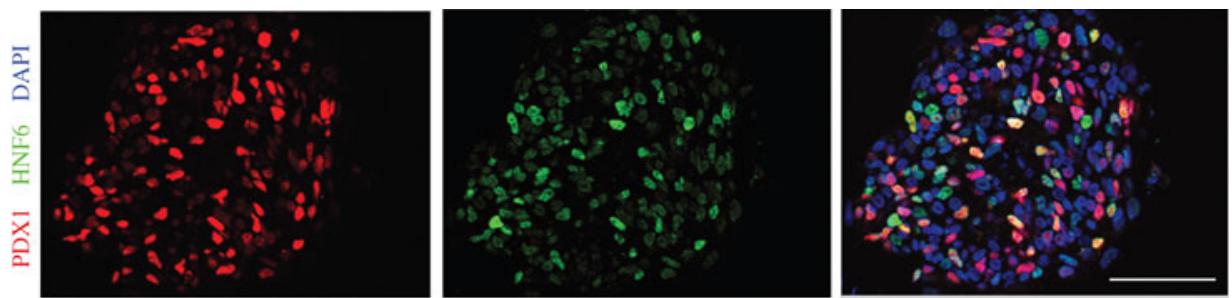

b
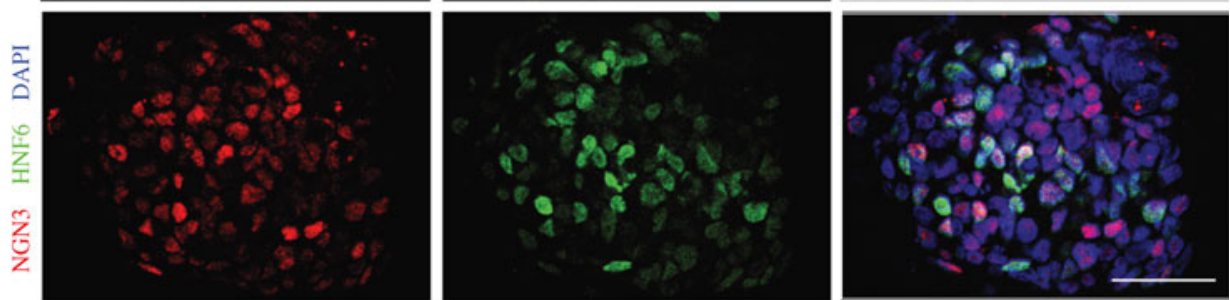

C
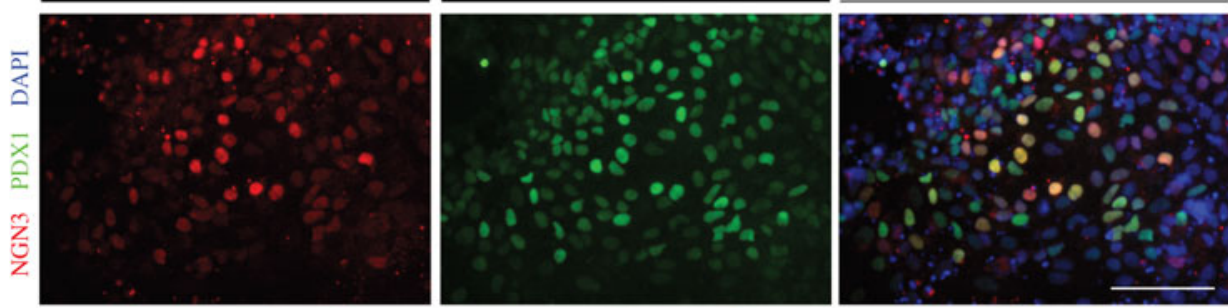

d
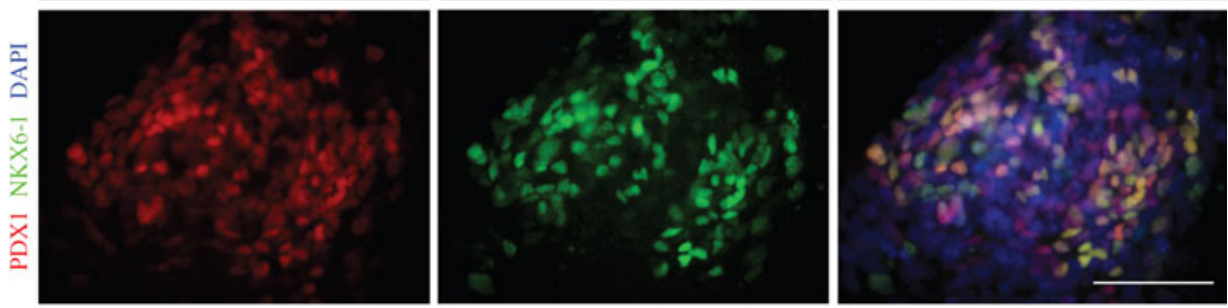

e
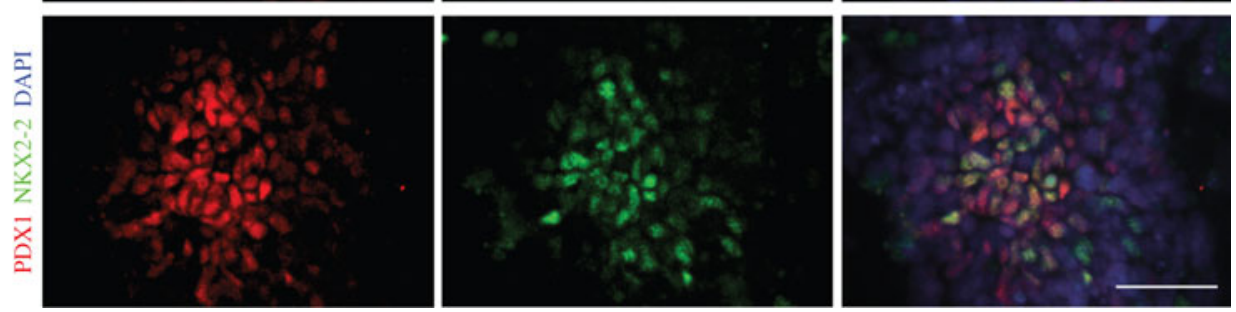

uptake from the culture medium (Fig. 5a). These cells coproduced PDX1 and NKX6-1, but did not produce other endocrine hormones, such as glucagon or somatostatin (Fig. 5b,c and data not shown). A small number of cells producing glucagon or somatostatin could be detected (ESM Fig. 6a,b). There were also a few amylase ${ }^{+}$exocrine cells (ESM Fig. 6c), and we could also detect the production of proprotein convertase subtilisin/kexin type 2 (PCSK2) (ESM Fig. 6d), an enzyme involved in processing proinsulin into insulin and C-peptide. FACS analyses showed that approximately $23.0 \%(21.1 \% \pm 5.8 \%$, $n=3$ ) of cells were insulin positive (Fig. 5d). Taken together, these results indicate that RM iPSCs can be differentiated into insulin-producing cells through a four-stage protocol in vitro.

We performed insulin content analysis of the insulinproducing cells and found it was approximately $8 \times 10^{-19}$ to
$10 \times 10^{-19} \mathrm{~mol} / \mathrm{cell}$. As it is currently difficult for us to obtain primary adult rhesus monkey beta cells, we could not evaluate how close the insulin content of RM iPSC-derived insulin-producing cells is to primary adult beta cells. To demonstrate the insulin release of insulin-producing cells, we incubated these cells with glucose at low $(2.5 \mathrm{mmol} / \mathrm{l})$ and high $(25 \mathrm{mmol} / \mathrm{l})$ concentrations. Results showed that there was about a 2.7 -fold $(p<0.05, n=3)$ increase in insulin secretion at the high glucose condition, suggesting that these insulin-producing cells have the ability to release insulin in response to glucose stimulation (Fig. 5e).

In vitro-generated insulin-producing cells could rescue STZ-treated diabetic mice We transplanted the final stage cells into the kidney capsules of NOD/SCID mice and examined the grafts after 2 months to assess the survival of these cells. We detected the presence of insulin-producing 
Fig. 4 Generation of mature insulin-producing cells in vivo; the grafts were removed from mice 8-10 weeks after transplantation of stage 3 differentiated cells. a,b Immunocytochemistry analysis showed that the $\mathrm{INS}^{+}$cells produce NKX6-1 and C-peptide (C-PEP). c-e $\mathrm{INS}^{+}$cells did not produce glucagon (GCG) or somatostatin (SST), although $\mathrm{GCG}^{+}$and $\mathrm{SST}^{+}$cells could be detected. Scale bars, $50 \mu \mathrm{m}(\mathbf{b}, \mathbf{e})$, $100 \mu \mathrm{m}(\mathbf{a}, \mathbf{c}-\mathbf{d})$ a
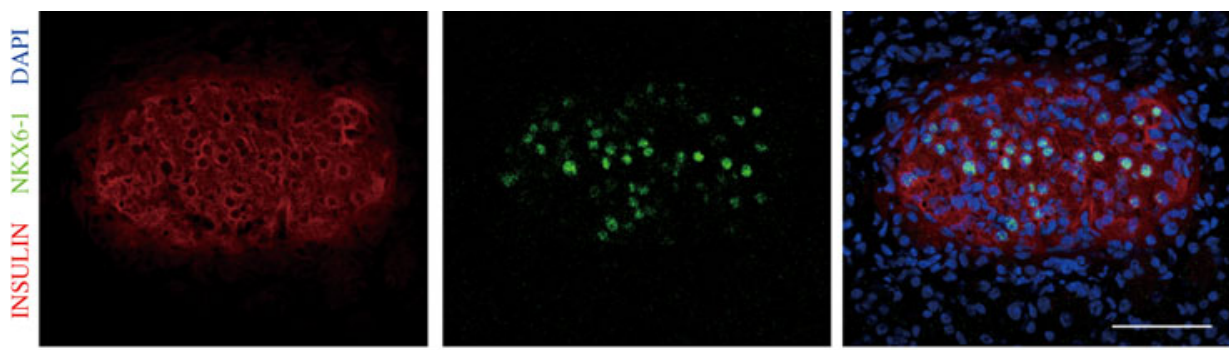

b
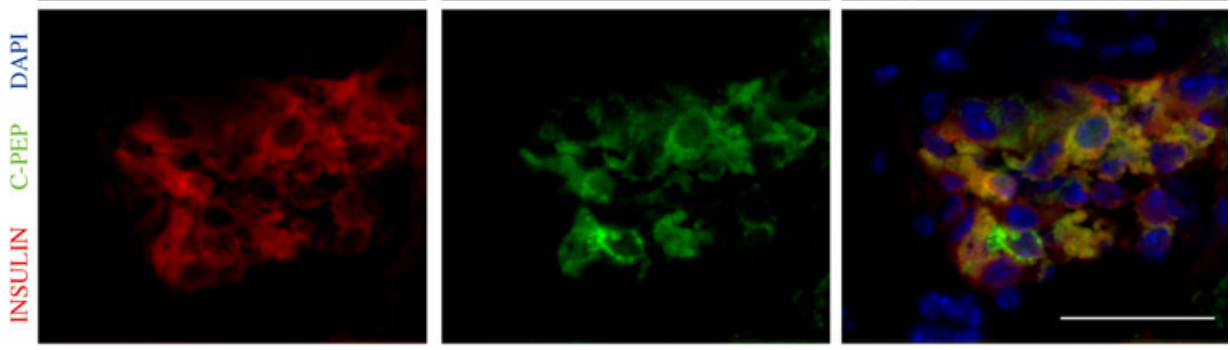

C

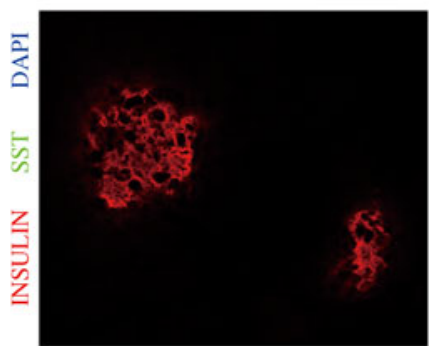

d
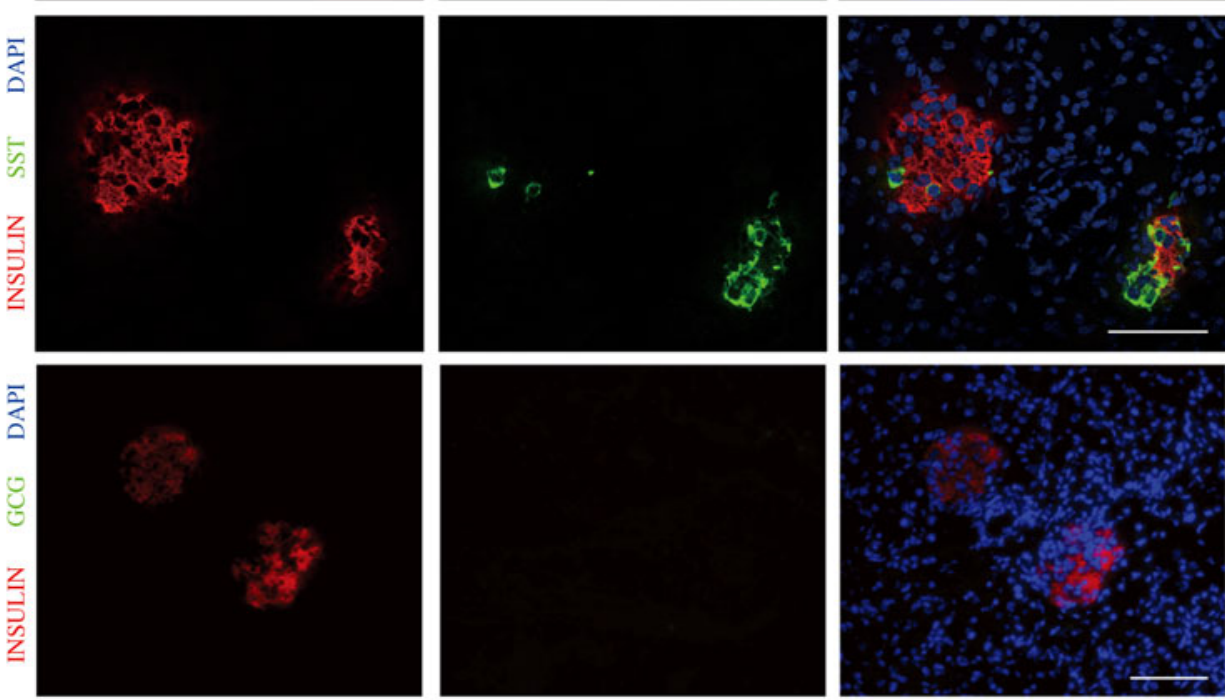

e
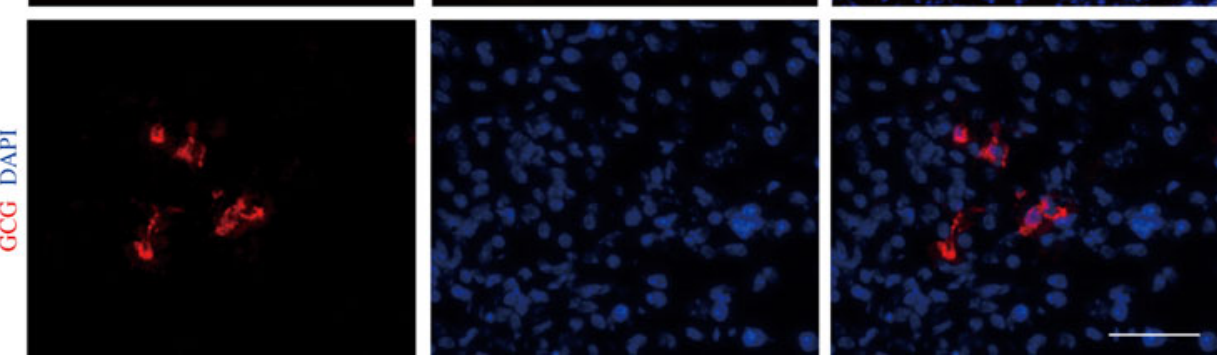

cells, which also produced C-peptide but did not produce glucagon or somatostatin (Fig. 6a-c). These results indicate that the insulin-producing cells survived during this period.

We then tried to determine the ability of these insulinproducing cells to regulate blood glucose levels in diabetic mouse models. We first generated diabetes models in NOD/ SCID mice by STZ treatment $(120 \mathrm{mg} / \mathrm{kg}$ of body weight) [31-33]; this dose of STZ was intended to result in a relatively lower mortality and higher rate of diabetic induction. Only STZ-treated mice with blood glucose above $13.9 \mathrm{mmol} / \mathrm{l}$ for $10-12$ consecutive days were used for further experiments. This $13.9 \mathrm{mmol} / \mathrm{l}$ criterion has been used in previous studies in our laboratory and by others [31, 34-36]. We stained insulin in the pancreas of these mice 12 days after STZ treatment, and found that there were only a few $\mathrm{INS}^{+}$cells remaining in these diabetic mouse models compared with normal untreated mice (ESM Fig. 7).

The final stage cells were implanted into the kidney capsules of diabetic NOD/SCID mouse models, with a control group implanted with PBS, and the glucose concentrations were observed for at least 45 days. In the control group $(n=8)$, the blood glucose concentration 
Fig. 5 Generation and characterisation of insulin-producing cells in vitro. a-c Immunocytochemistry analysis showed that, at the end of stage 4, PDX $1^{+}$ cells produce NKX6-1 and C-peptide (C-PEP), and the INS $^{+}$cells also produce C-peptide. d FACS analysis showed that approximately $23.0 \% \mathrm{INS}^{+}$cells are generated. e Glucose-stimulated insulin secretion analysis showed that the insulin secretion of the stage 4 differentiated cells in a high concentration glucose environment is about 2.7 -fold $(p<0.05)$ of that secreted in a low concentration glucose environment. Scale bars, $50 \mu \mathrm{m}$. Data represent mean $\pm \mathrm{SD}$, and error bars indicate SD. Undif, undifferentiated; Dif, differentiated; FSC, forward scatter; Similar results were obtained in at least three independent experiments a
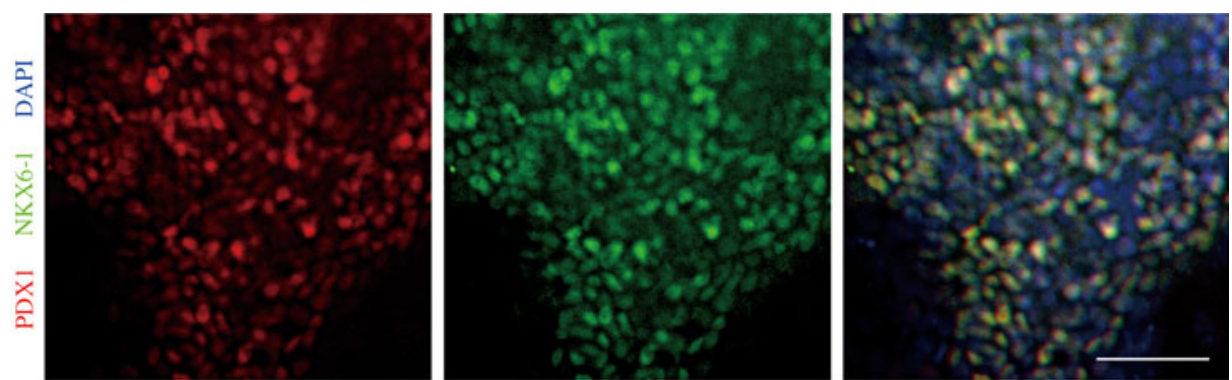

b
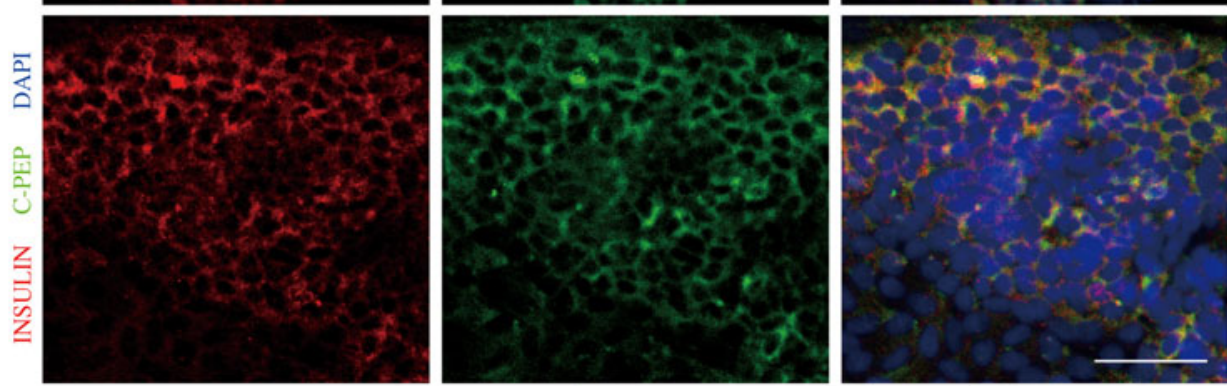

c
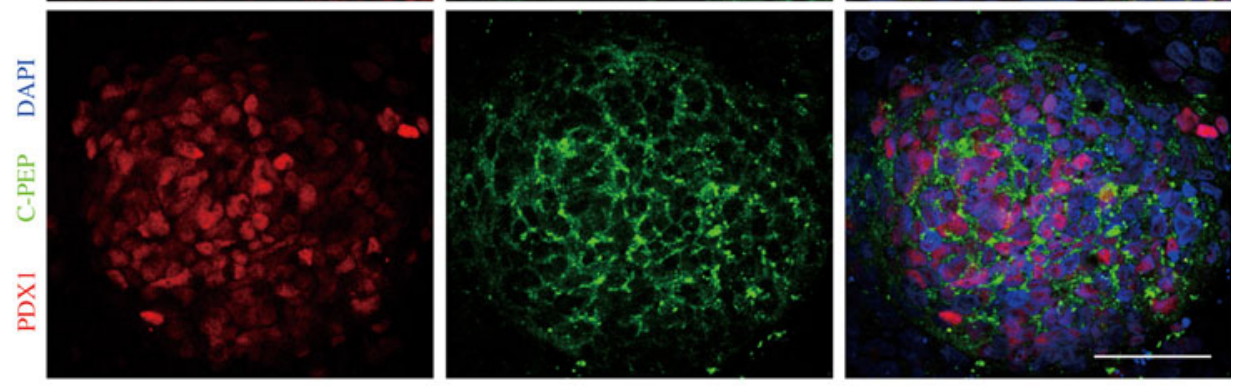

d
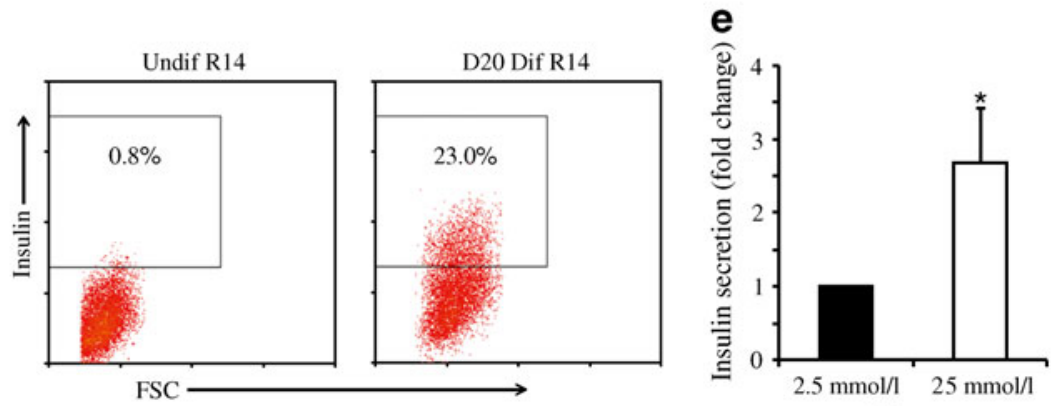

Glucose remained high, and did not decrease below $13.9 \mathrm{mmol} / \mathrm{l}$ in any of these diabetic mouse models. In the cell-implanted mice, the blood glucose exhibited different trends and mice were divided into two groups accordingly $(n=8$ for each group). In both groups, the blood glucose level decreased in the first week. Over the following 5 weeks, the levels of blood glucose in group 1 mice further decreased to below $13.9 \mathrm{mmol} / \mathrm{l}$ (Fig. 6d), while in group 2, the blood glucose subsequently increased and remained hyperglycaemic (data not shown). The proportion of euglycaemic mice after cell transplantation was 50\%. Therefore, these results demonstrate that insulin-producing cells differentiated from RM iPSCs can regulate glucose metabolism to rescue hyperglycaemia in some diabetic mouse models.

\section{Discussion}

In this paper we have described a new four-stage protocol for the pancreatic differentiation of RM iPSCs, and each stage of differentiation was characterised by specific gene expression analysis (Figs 2, 3 and 5, ESM Fig. 2). We demonstrate for the first time that insulin-producing cells can be generated from non-human primate iPSCs.

Several previous studies have attempted the pancreatic differentiation of human iPSCs $[9,12,20]$. Tateishi et al. [12] first reported the generation of insulin-producing isletlike clusters containing both C-peptide-positive and glucagon-positive cells from human iPSCs by using Jiang's protocol [21]. In our laboratory, we obtained PDX1 and C-peptide double positive cells from human iPSCs based on 
Fig. 6 Transplantation assay of $\mathrm{RM}$ iPSC in vitro-derived insulin-producing cells in a mouse model for diabetes. a-c Immunocytochemistry analysis for grafts from mice transplanted with stage 4 differentiated RM iPSCs showed that the $\mathrm{INS}^{+}$ cells produce C-peptide (C-PEP), but do not produce glucagon (GCG) or somatostatin (SST). d Some diabetic mouse models (group 1, $n=8$; black line) implanted with final stage cells could regulate blood glucose to a normal level. The control diabetic mouse models ( $n=8$; dotted line) implanted with PBS maintained high levels of blood glucose at all times. Scale bar, $100 \mu \mathrm{m}$. Data represent mean $\pm \mathrm{SD}$, and error bars indicate SD a
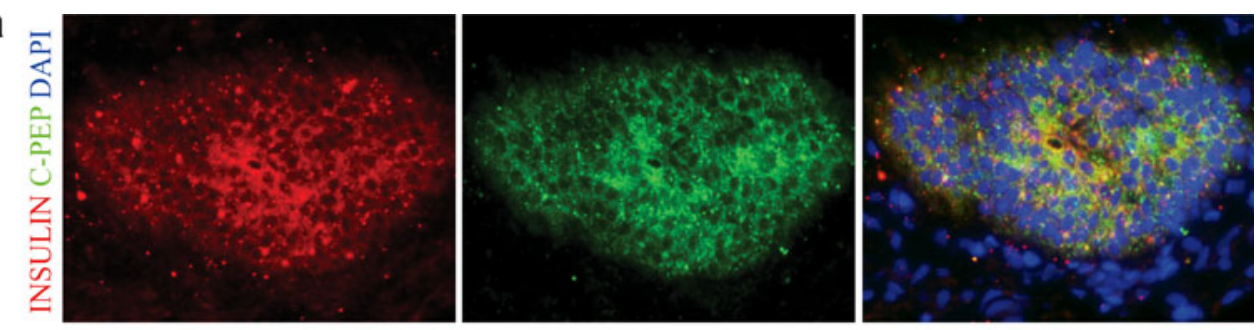

b
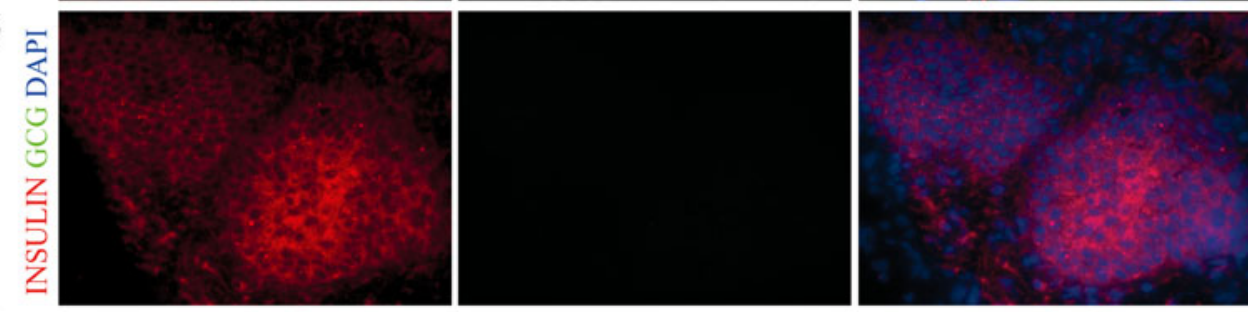

C
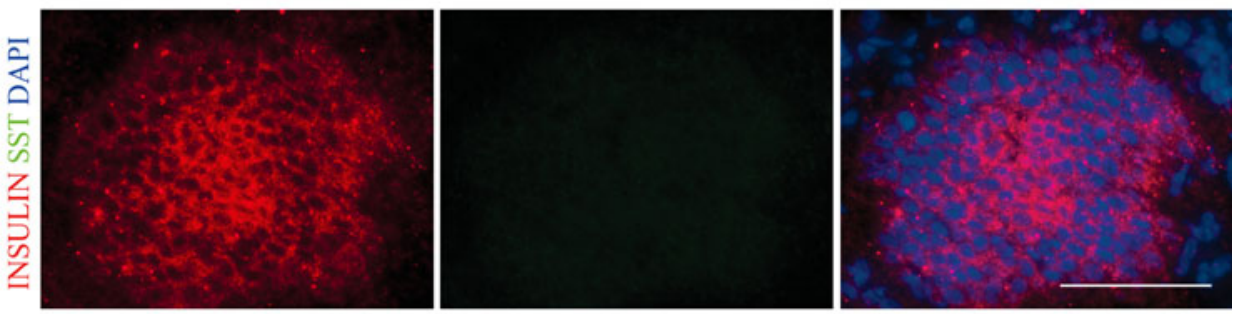

d

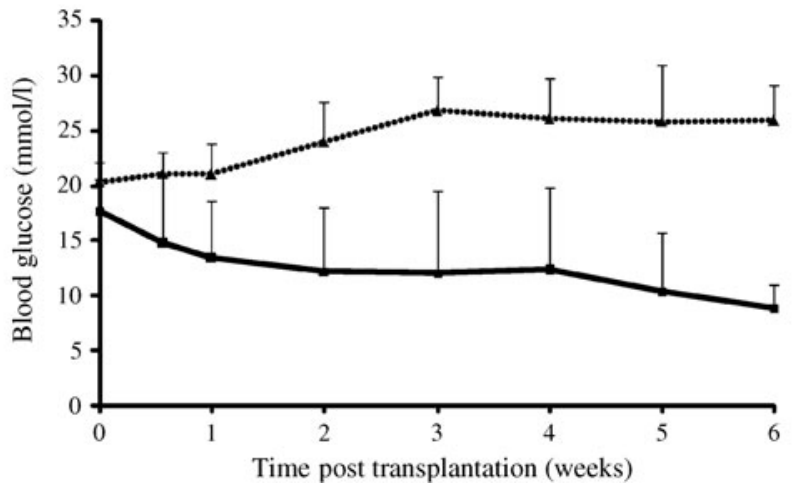

our optimal strategy for human ESCs [20]. Maehr et al. demonstrated that iPSCs can be generated from patients with type 1 diabetes and could be subsequently differentiated into insulin-producing cells [9]. However, none of these studies examined the in vivo function of iPSC-derived insulin-producing cells $[9,12,20]$. In the present study, we transplanted RM iPSC-derived insulin-producing cells into immunodeficient diabetic mouse models to assess their function. We found that these cells could survive for at least 2 months in vivo, co-producing PDX1, NKX6-1 and C-peptide. Moreover, these insulin-producing cells could restore approximately $50 \%$ of diabetic mouse models to euglycaemia.

In this study, we established a quantitative system using flow cytometry analysis to evaluate the differentiation efficiency. We chose CXCR4 as a marker for DE cells [37], PDX1 as a marker for PP cells [38, 39] and insulin as a marker for insulin-producing cells. Our FACS data presented here demonstrate that the generation of $\mathrm{DE}$ and PP cells can be achieved at very high efficiency (Fig. 2 and ESM Fig. 2), while further differentiation into insulinproducing cells is inefficient (Fig. 5). Immunostaining experiments further confirmed these results. This indicates that, in future work, identification of the critical signals and optimisation of the differentiation conditions for PP cells to generate EP cells, and then insulin-producing cells, from iPSCs need to be further investigated.

In our protocol, the high efficiency of over $85 \%$ for generating $\mathrm{PDX} 1^{+} \mathrm{PP}$ cells from RM iPSCs was due to the optimisation of the procedure following the DE stage, according to a recent report in our laboratory [26]. However, our previous work did not use in vivo assays to examine whether the disruption and re-establishment of cell-cell contact would affect the maturation and functioning of insulin-producing cells. In the present work, we transplanted the differentiated cells in stages 3 and 4 from RM 
iPSCs into immunodeficient mice and detected the presence of insulin-producing cells in the grafts (Figs 4 and 6). Therefore, our results provide evidence that cell dissociation at the end of the DE stage is crucial for efficient PP differentiation and does not prevent the generation of insulinproducing cells.

During the process of directed differentiation from RM iPSCs into insulin-producing cells, we obtained $\mathrm{NGN}^{+} \mathrm{EP}$ cells at the end of stage 3 . In pancreatic development, beta cells are generated from a transient population of $\mathrm{NGN}^{+}$ EP cells [40]. However, in previous reports on pancreatic differentiation from iPSCs, generation of $\mathrm{NGN}^{+}$EP cells has not been demonstrated $[9,12,20]$. In the present study, we obtained $\mathrm{NGN}^{+}$cells, most of which co-produced PDX1 and HNF6 (Fig. 3). Moreover, we demonstrated for the first time the competence of primate iPSC-derived EP cells to produce insulin-producing cells in vivo. Similarly, a previous study demonstrated that transplantation of hESCderived pancreatic endoderm in mice could generate insulin-producing cells in vivo [41]. The transplanted cells in this study produce PDX1, FOXA2 and HNF6, and some produce NKX6-1, indicating a cell fate as PP cells. Our transplanted RM iPSC-derived stage 3 cells produced PDX1, NGN3, NKX6-1 and NKX2-2 (Fig. 3), and were referred to as pancreatic EP cells. Therefore, the in vivo maturation competence of cells was demonstrated at a later differentiation stage than in the previous report, which also indicates the validity of our differentiation protocol for the generation of insulin-producing cells.

We identified the chemical compound SB431542 that, in the presence of EGF, promoted the generation of $\mathrm{NGN}^{+}$ EP cells. SB431542 specifically antagonises TGF- $\beta$ signalling by inhibiting type 1 activin receptor-like kinase (ALK) receptors ALK4, ALK5 and ALK7. The roles of TGF- $\beta$ in pancreatic development have been previously reported [27, 42-44]. In several studies, inactivation of TGF- $\beta$ signalling in mice either by generation of activin receptor mutants $[42,43]$ or conditional generation of SMAD family member 7 (SMAD7) [44] decreased endocrine cell differentiation and resulted in islet hyperplasia. In another study, mice deficient in growth differentiation factor (GDF) 11 harboured increased numbers of NGN3 ${ }^{+}$EP cells, although their beta cell number was reduced [27]. Our results suggest that inhibition of TGF- $\beta$ signalling could promote $\mathrm{NGN}^{+}$endocrine specification, which is consistent with a recent report regarding pancreatic differentiation of human ESCs [45].

In summary, our results demonstrate that insulin-producing cells can be generated by this stepwise differentiation method from RM iPSCs. In the future, we will transplant these insulin-producing cells into the corresponding rhesus monkey model for diabetes to further investigate the efficacy and safety of autologous iPSC-derived beta- like cells for type 1 diabetes therapy in rhesus monkey models.

Acknowledgements The authors thank I.C. Bruce and R. Armstrong for critical reading of this manuscript; W. Jiang, S. Chen, H. Liu, M. Liu, Y. Liu, Y. Han and other colleagues in our laboratory for advice during experiments; and Y. Zhang for performing real-time PCR. This research was supported by the National Natural Science Foundation of China (30830061 and 90919031), Chinese Science and Technology Key Project (2011ZX09102-010-03), Science and Technology Plan of the Beijing Municipal Government (D07050701350705), National 863 Program, National Basic Research Program for China (973 Program 2009CB941203), 111 Project and Beijing Natural Science Foundation (5100002) to H. Deng.

Contribution statement Conception and design, and drafting the article: F.F.Z., P.B.Z., D.H.Z., M.X.D., H.K.D; analysis and interpretation of data, and revising it critically for important intellectual content: F.F.Z., P.B.Z., X.S., M.Y., T.T.X., Y.S. All authors approved the final version.

Duality of interest The authors declare that there is no duality of interest associated with this manuscript.

\section{References}

1. Takahashi K, Yamanaka S (2006) Induction of pluripotent stem cells from mouse embryonic and adult fibroblast cultures by defined factors. Cell 126:663-676

2. Takahashi K, Tanabe K, Ohnuki M et al (2007) Induction of pluripotent stem cells from adult human fibroblasts by defined factors. Cell 131:861-872

3. Yu J, Vodyanik MA, Smuga-Otto $\mathrm{K}$ et al (2007) Induced pluripotent stem cell lines derived from human somatic cells. Science 318:1917-1920

4. Park IH, Zhao R, West JA et al (2008) Reprogramming of human somatic cells to pluripotency with defined factors. Nature 451:141-146

5. Park IH, Arora N, Huo H et al (2008) Disease-specific induced pluripotent stem cells. Cell 134:877-886

6. Dimos JT, Rodolfa KT, Niakan KK et al (2008) Induced pluripotent stem cells generated from patients with ALS can be differentiated into motor neurons. Science 321:1218-1221

7. Ebert AD, Yu J, Rose FF Jr et al (2009) Induced pluripotent stem cells from a spinal muscular atrophy patient. Nature 457:277280

8. Soldner F, Hockemeyer D, Beard C et al (2009) Parkinson's disease patient-derived induced pluripotent stem cells free of viral reprogramming factors. Cell 136:964-977

9. Maehr R, Chen S, Snitow M et al (2009) Generation of pluripotent stem cells from patients with type 1 diabetes. Proc Natl Acad Sci U S A 106:15768-15773

10. Choi KD, Yu J, Smuga-Otto K et al (2009) Hematopoietic and endothelial differentiation of human induced pluripotent stem cells. Stem Cells 27:559-567

11. Chambers SM, Fasano CA, Papapetrou EP, Tomishima M, Sadelain M, Studer L (2009) Highly efficient neural conversion of human ES and iPS cells by dual inhibition of SMAD signaling. Nat Biotechnol 27:275-280

12. Tateishi K, He J, Taranova O, Liang G, D’Alessio AC, Zhang Y (2008) Generation of insulin-secreting islet-like clusters from human skin fibroblasts. J Biol Chem 283:31601-31607 
13. Song Z, Cai J, Liu Y et al (2009) Efficient generation of hepatocyte-like cells from human induced pluripotent stem cells. Cell Res 19:1233-1242

14. Hanna J, Wernig M, Markoulaki S (2007) Treatment of sickle cell anemia mouse model with iPS cells generated from autologous skin. Science 318:1920-1923

15. Wernig M, Zhao JP, Pruszak J et al (2008) Neurons derived from reprogrammed fibroblasts functionally integrate into the fetal brain and improve symptoms of rats with Parkinson's disease. Proc Natl Acad Sci U S A 105:5856-5861

16. Xu D, Alipio Z, Fink LM et al (2009) Phenotypic correction of murine hemophilia A using an iPS cell-based therapy. Proc Natl Acad Sci U S A 106:808-813

17. Alipio Z, Liao W, Roemer EJ et al (2010) Reversal of hyperglycemia in diabetic mouse models using induced-pluripotent stem (iPS)derived pancreatic beta-like cells. Proc Natl Acad Sci U S A 107:13426-13431

18. Liu H, Zhu F, Yong J et al (2008) Generation of induced pluripotent stem cells from adult rhesus monkey fibroblasts. Cell Stem Cell 3:587-590

19. Shapiro AM, Lakey JR, Ryan EA et al (2000) Islet transplantation in seven patients with type 1 diabetes mellitus using a glucocorticoid-free immunosuppressive regimen. N Engl J Med 343:230-238

20. Zhang D, Jiang W, Liu M et al (2009) Highly efficient differentiation of human ES cells and iPS cells into mature pancreatic insulin-producing cells. Cell Res 19:429-438

21. Jiang J, Au M, Lu K et al (2007) Generation of insulin-producing islet-like clusters from human embryonic stem cells. Stem Cells 25:1940-1953

22. Chen S, Borowiak M, Fox JL et al (2009) A small molecule that directs differentiation of human ESCs into the pancreatic lineage. Nat Chem Biol 5:258-265

23. Osafune K, Caron L, Borowiak M et al (2008) Marked differences in differentiation propensity among human embryonic stem cell lines. Nat Biotechnol 26:313-315

24. D'Amour KA, Bang AG, Eliazer S et al (2006) Production of pancreatic hormone-expressing endocrine cells from human embryonic stem cells. Nat Biotechnol 24:1392-1401

25. Oliver-Krasinski JM, Stoffers DA (2008) On the origin of the beta cell. Genes Dev 22:1998-2021

26. Cai J, Yu C, Liu Yet al (2010) Generation of homogeneous PDX1 $(+)$ pancreatic progenitors from human ES cell-derived endoderm cells. J Mol Cell Biol 2:50-60

27. Harmon EB, Apelqvist AA, Smart NG, Gu X, Osborne DH, Kim SK (2004) GDF11 modulates $\mathrm{NGN3}^{+}$islet progenitor cell number and promotes beta-cell differentiation in pancreas development. Development 131:6163-6174

28. Oliver-Krasinski JM, Kasner MT, Yang J et al (2009) The diabetes gene Pdx1 regulates the transcriptional network of pancreatic endocrine progenitor cells in mice. J Clin Invest 119:1888-1898

29. Schwitzgebel VM, Scheel DW, Conners JR et al (2000) Expression of neurogenin3 reveals an islet cell precursor population in the pancreas. Development 127:3533-3542
30. Gu G, Dubauskaite J, Melton DA (2002) Direct evidence for the pancreatic lineage: $\mathrm{NGN3}^{+}$cells are islet progenitors and are distinct from duct progenitors. Development 129:2447-2457

31. Kojima H, Fujimiya M, Matsumura K et al (2003) NeuroDbetacellulin gene therapy induces islet neogenesis in the liver and reverses diabetes in mice. Nat Med 9:596-603

32. Sabek OM, Fraga DW, Minoru O, McClaren JL (2005) Gaber AO (2005) Assessment of human islet viability using various mouse models. Transplant Proc 37:3415-3416

33. Smukler SR, Arntfield ME, Razavi R et al (2011) The adult mouse and human pancreas contain rare multipotent stem cells that express insulin. Cell Stem Cell 8:281-293

34. Blyszczuk P, Czyz J, Kania G et al (2003) Expression of Pax4 in embryonic stem cells promotes differentiation of nestin-positive progenitor and insulin-producing cells. Proc Natl Acad Sci U S A 100:998-1003

35. Shi Y, Hou L, Tang F et al (2005) Inducing embryonic stem cells to differentiate into pancreatic beta cells by a novel three-step approach with activin A and all-trans retinoic acid. Stem Cells 23:656-662

36. Jiang W, Shi Y, Zhao D et al (2007) In vitro derivation of functional insulin-producing cells from human embryonic stem cells. Cell Res 17:333-344

37. D'Amour KA, Agulnick AD, Eliazer S, Kelly OG, Kroon E, Baetge EE (2005) Efficient differentiation of human embryonic stem cells to definitive endoderm. Nat Biotechnol 23:1534-1541

38. Jonsson J, Carlsson L, Edlund T, Edlund H (1994) Insulinpromoter-factor 1 is required for pancreas development in mice. Nature 371:606-609

39. Gu G, Brown JR, Melton DA (2003) Direct lineage tracing reveals the ontogeny of pancreatic cell fates during mouse embryogenesis. Mech Dev 120:35-43

40. Gradwohl G, Dierich A, LeMeur M, Guillemot F (2000) neurogenin3 is required for the development of the four endocrine cell lineages of the pancreas. Proc Natl Acad Sci U S A 97:1607-1611

41. Kroon E, Martinson LA, Kadoya K et al (2008) Pancreatic endoderm derived from human embryonic stem cells generates glucose-responsive insulin-secreting cells in vivo. Nat Biotechnol 26:443-452

42. Shiozaki S, Tajima T, Zhang YQ, Furukawa M, Nakazato Y, Kojima I (1999) Impaired differentiation of endocrine and exocrine cells of the pancreas in transgenic mouse expressing the truncated type II activin receptor. Biochim Biophys Acta 1450:1-11

43. Yamaoka T, Idehara C, Yano M et al (1998) Hypoplasia of pancreatic islets in transgenic mice expressing activin receptor mutants. J Clin Invest 102:294-301

44. Smart NG, Apelqvist AA, Gu X et al (2006) Conditional expression of Smad7 in pancreatic beta cells disrupts TGF-beta signaling and induces reversible diabetes mellitus. PLoS Biol 4:e39

45. Rezania A, Riedel MJ, Wideman RD et al (2010) Production of functional glucagon-secreting alpha cells from human embryonic stem cells. Diabetes 60:239-247 